\title{
norden
}

\section{A Nordic strategy for collection, sorting, reuse and recycling of textiles}
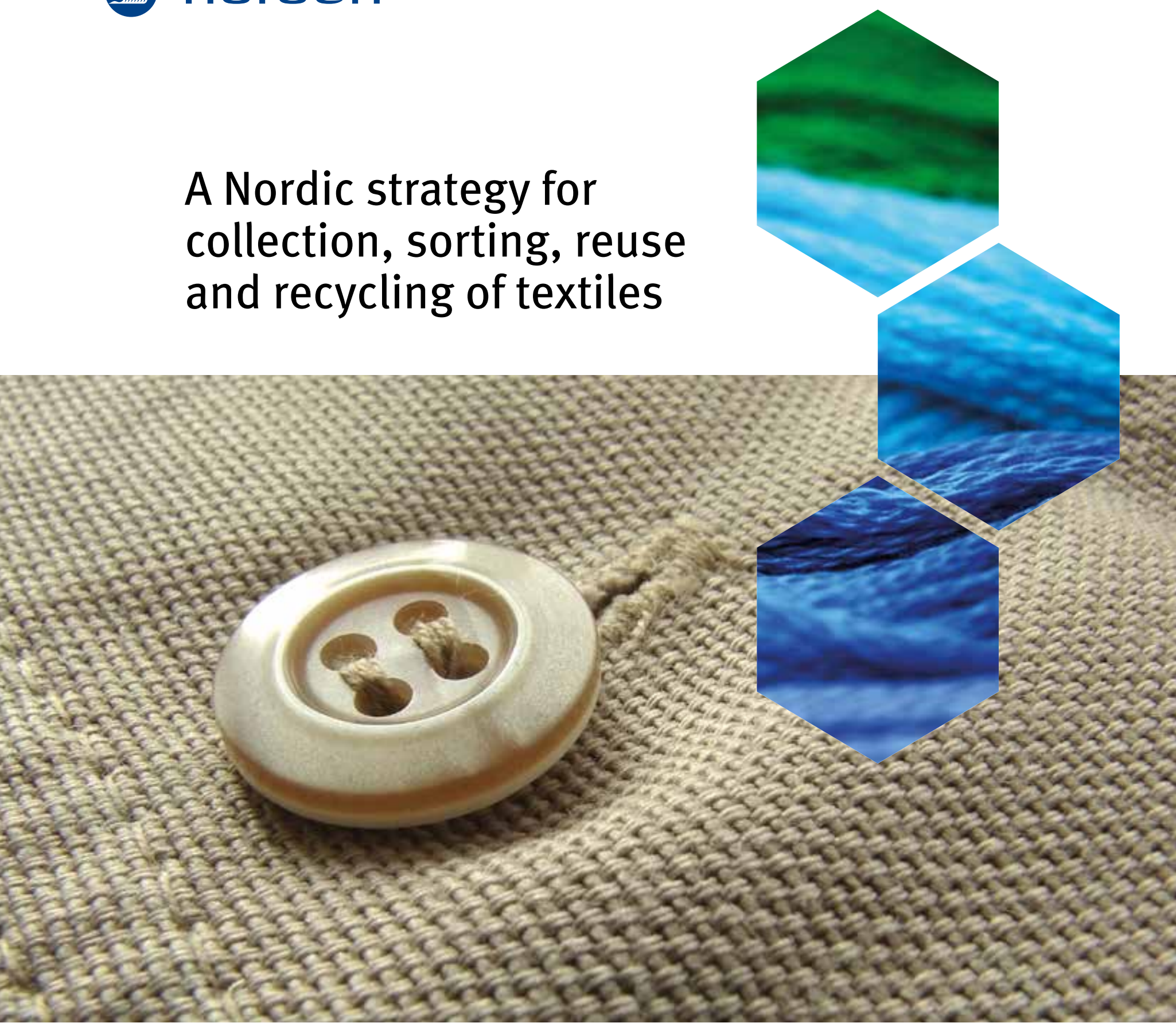

/Policy brief 


\section{A Nordic strategy for collection, sorting, reuse} and recycling of textiles

ISBN 978-92-893-4021-2 (PRINT)

ISBN 978-92-893-4022-9 (PDF)

http://dx.doi.org/10.6027/ANP2015-720

ANP 2015:720

(C) Nordic Council of Ministers 2015

Authors: Maria Elander, IVL Swedish

Environmental Research Institute,

David Palm, IVL Swedish Environmental

Research Institute

Layout: Gitte Wejnold

Cover photo: SignElements

Photo: SignElements

Print: Rosendahls-Schultz Grafisk

Copies: 100

Typeface: Meta LF

Paper: Munken Polar

\section{Printed in Denmark}

www.norden.org/en/publications

\section{Nordic co-operation}

Nordic co-operation is one of the world's most extensive forms of regional collaboration, involving Denmark, Finland, Iceland, Norway, Sweden, and the Faroe Islands, Greenland, and Åland.

Nordic co-operation has firm traditions in politics, the economy, and culture. It plays an important role in European and international collaboration, and aims at creating a strong Nordic community in a strong Europe.

Nordic co-operation seeks to safeguard Nordic and regional interests and principles in the global community. Common Nordic values help the region solidify its position as one of the world's most innovative and competitive.

\section{Nordic Council of Ministers}

Ved Stranden 18

DK-1061 Copenhagen K

Telefon (+45) 33960200

www.norden.org 


\section{A Nordic strategy for collection, sorting, reuse and recycling of textiles}

Policy brief

Maria Elander, IVL Swedish Environmental Research Institute

David Palm, IVL Swedish Environmental Research Institute 


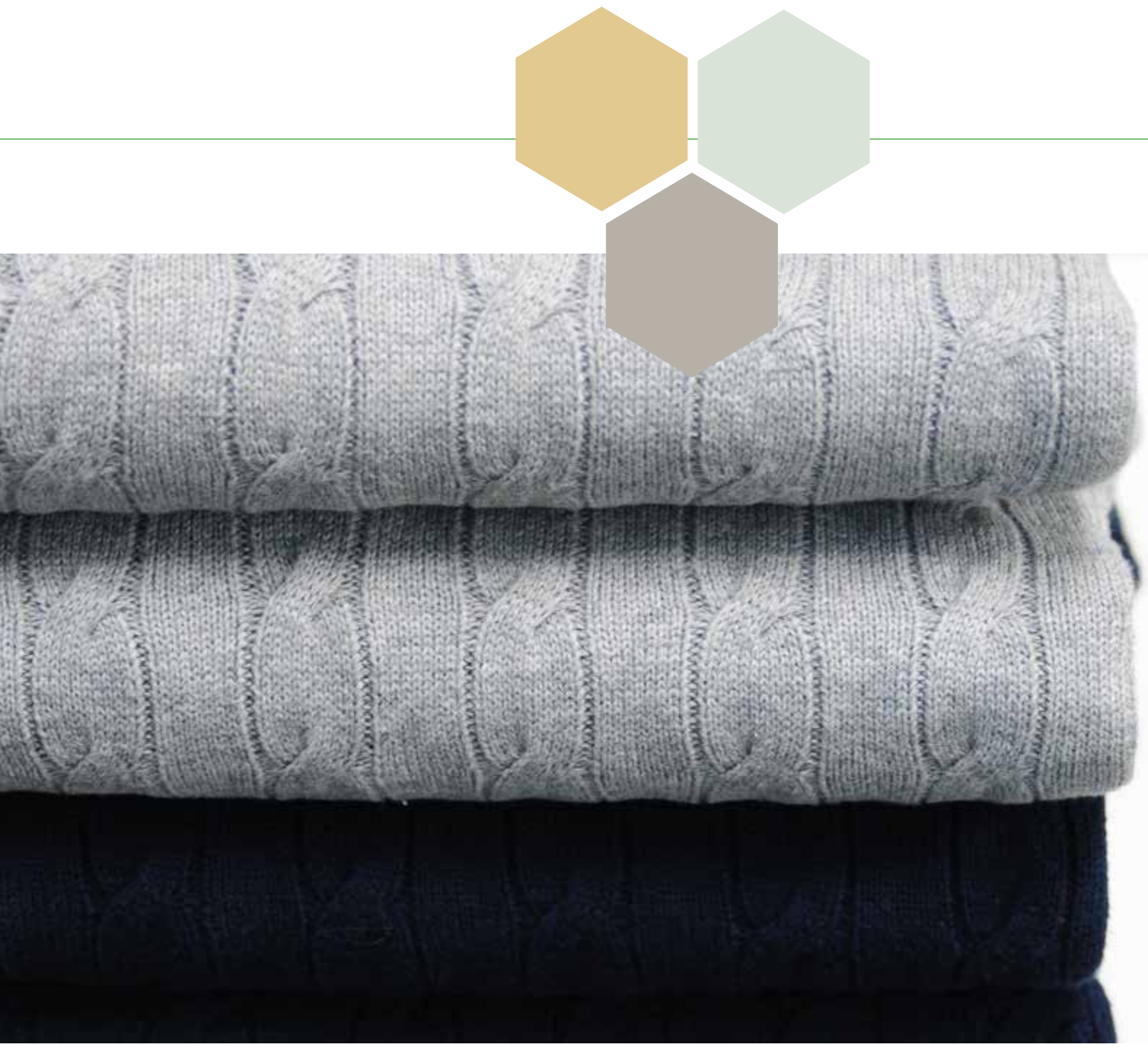




\section{Introduction}

There is large need and potential to increase reuse and recycling of used textiles in the Nordic region in order to reduce their environmental impacts. The Nordic Strategy is one important piece of the puzzle to make the Nordic textile sector more sustainable, but additional measures focused on the production of textiles are necessary.

To reach significant changes with an increase in reuse and recycling of used textiles both a high level of cooperation between the
Nordic countries and a high level of innovation is needed. Binding targets for more resource efficient management of used textiles and textile wastes must be defined and accompanied with policy measures as well as supporting structures for implementation.

Increased reuse and recycling of textiles and textile wastes have a significant potential to create increased employment in the Nordic region.
This policy brief includes key results and findings from the project $A$ Nordic Strategy for collection, sorting, reuse and recycling of textiles, as well as key recommendations for action. The project is part of the Nordic Prime Ministers' initiative, The Nordic Region - leading in green growth.

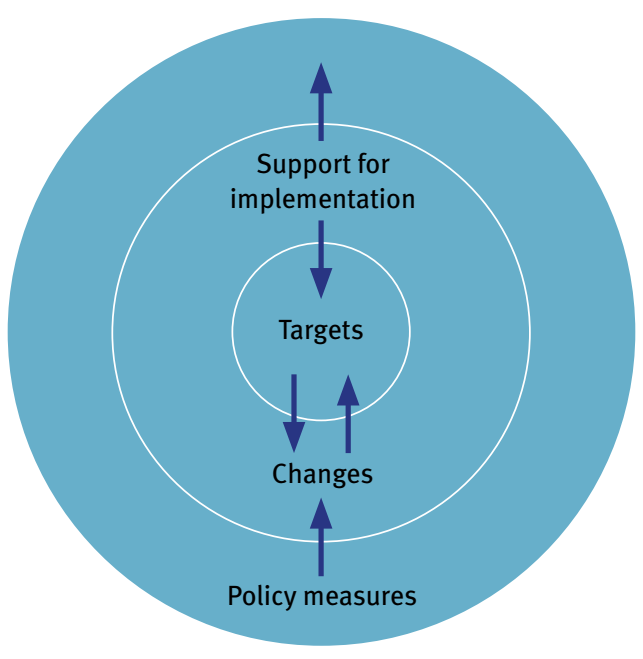




\section{Key messages for policy makers}

Every year 350000 tonnes of textiles are consumed in the Nordic region. If current trends continue, the consumption will have increased to 450000 tonnes in 2020. Currently only 120000 tonnes of used textiles are separately collected per year, corresponding to about a third of the new textiles put on the market. Environmental impacts from textiles are high considering a life cycle perspective. Every kilogram of textiles causes on average emissions corresponding to 15 kilograms of carbon dioxide equivalents with cotton as the most common fabric, requiring on average 10000 litres of water in some of the world's most water stressed areas.

The relative environmental impacts of textiles can be reduced by prolonging their active lifetime, e.g. by reusing them, and closing textile material loops through recycling. On behalf of the Nordic
Council of Ministers a Nordic strategy for collection, sorting, reuse and recycling of textiles was developed.

The strategy proposes 14 policy measures for increasing reuse and recycling of used textiles in the Nordic region along with supporting structures for implementation of the strategy. It analyses the role of and impacts on stakeholders and identifies key actors for successful implementation. 
Increasing collection, sorting, reuse and recycling of textiles in line with the strategy comprises potentials to create significant increases in employment - potentially more than 4000 new green jobs - and position the Nordic region as a forerunner in resource efficient use and handling of used textiles.

The strategy poses one important cogwheel in making the Nordic textile sector more sustainable.
However, the scope of the strategy only comprises the consumption and end of life phase of textiles. In order to create a sustainable textile sector, additional strategies and measures targeting specifically the production phase are necessary.

Recommendations for action vary depending on policy level (e.g. Nordic, national and municipal level) and whether primarily the political or administrative level is addressed.
Whereas the strategy includes policy measures on all of these levels, the following key recommendations focus on political decision makers on Nordic and national levels.

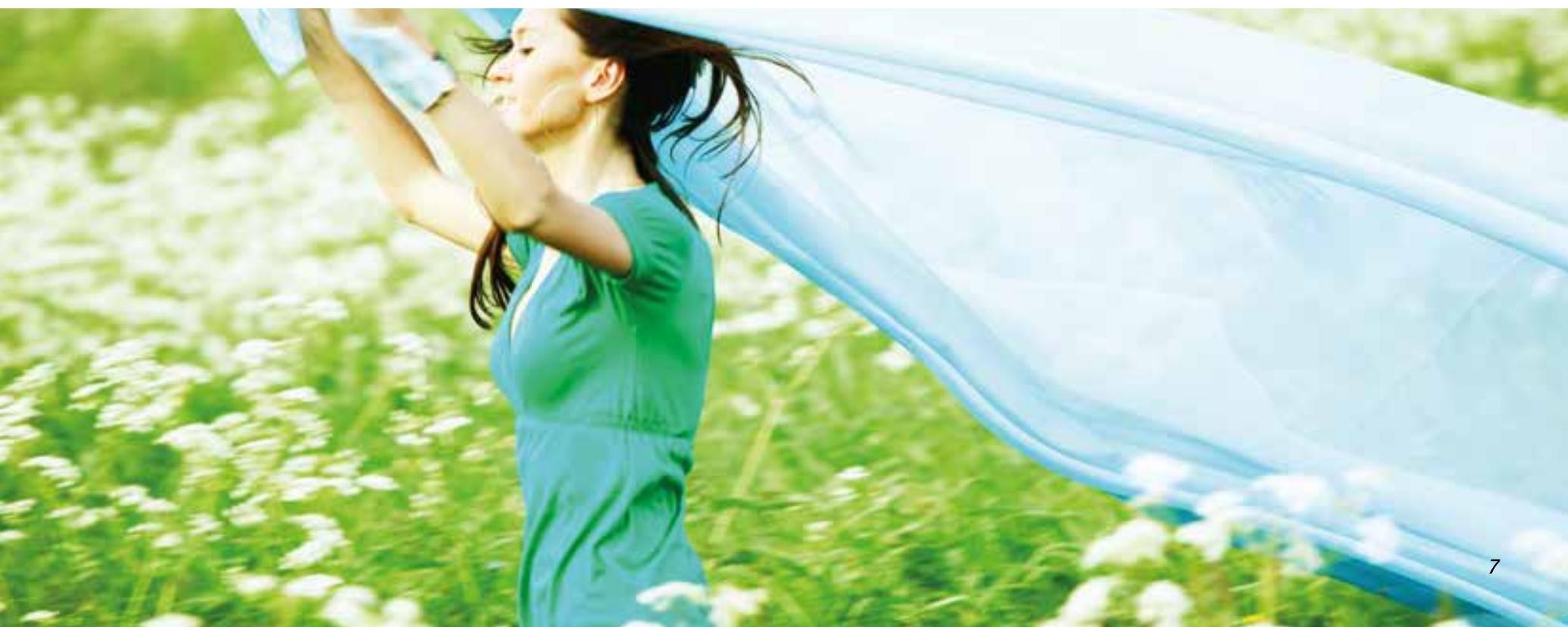



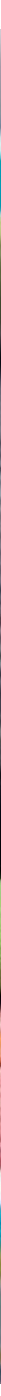


\section{Key recommendations for action}

In order to increase collection, reuse and recycling of textiles and, as a result, reduce the environmental impacts of textiles, Nordic decision makers are called to:

\section{Define ambitious and clear} binding targets for collection, sorting, reuse and recycling of used textiles. The targets should include minimum targets on Nordic levels, allowing more ambitious national targets. Each target should be accompanied by interim targets, enabling assessment and prognosis of target achievement.

\section{Introduce policy measures} securing target achievement for the defined targets for collection, sorting, reuse and recycling of used textiles. Some policy measures can be coordinated on Nordic level.

\section{Create a structure for Nordic} cooperation within the field of textiles and textile wastes, including a forum with government officials from all Nordic countries. This forum should be given the mandate and resources to discuss and decide on common issues, such as e.g. methodologies for data collection and assessment as well as coordination of policy measures on a Nordic level. The forum should consider and support exchange of best practices in the field of textiles.

\section{Evaluate and support business} models in the field of collective use, reuse and prolonged (active) lifetime of textiles financially.

\section{Endorse the mandatory use of} only certified actors involved in collection, sorting, selling for reuse and recycling of used textiles in accordance with The Nordic textile reuse and recycling commitment.
6. Lead by example by developing clear guidance on public procurement for reuse of textiles and textiles with recycled content and by collecting used textiles from all public activities and public businesses.

\section{Investigate the need and} potentials for an automated sorting facility for used textiles in the Nordic region. To allow for sufficient scale, this should be done on a Nordic level.

\section{Support research and} development of new technologies for (chemical) textile-to-textile recycling. 


\section{Objective of the research performed}

The objective of the research project was to develop a strategy for improved handling of textiles in order to increase reuse and recycling of textiles and reduce the environmental impacts from textile consumption.

The developed strategy focuses on collection, sorting, reuse and recycling of used textiles and gives priority for reuse over recycling.
With the current market situation and available options for collection, sorting, reuse and recycling as a starting point, the strategy identifies necessary changes and suggests policy measures for increased reuse and recycling of textiles.

\section{Need for Nordic innovation}

Four different scenarios were described and evaluated with regard to how well they would promote increased collection rates, priority for reuse before recycling as well as high quality recycling of textiles (see Figure 1). The evaluation showed that only the Nordic innovation scenario, characterized by both a high level of change and a high level of cooperation, is able to meet these objectives.

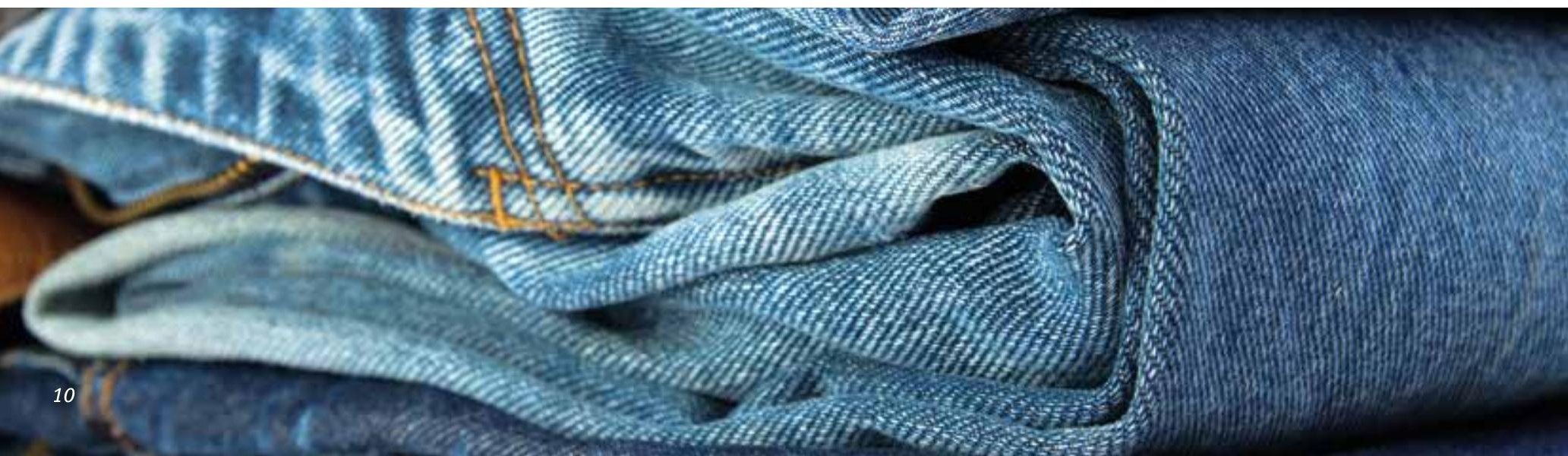




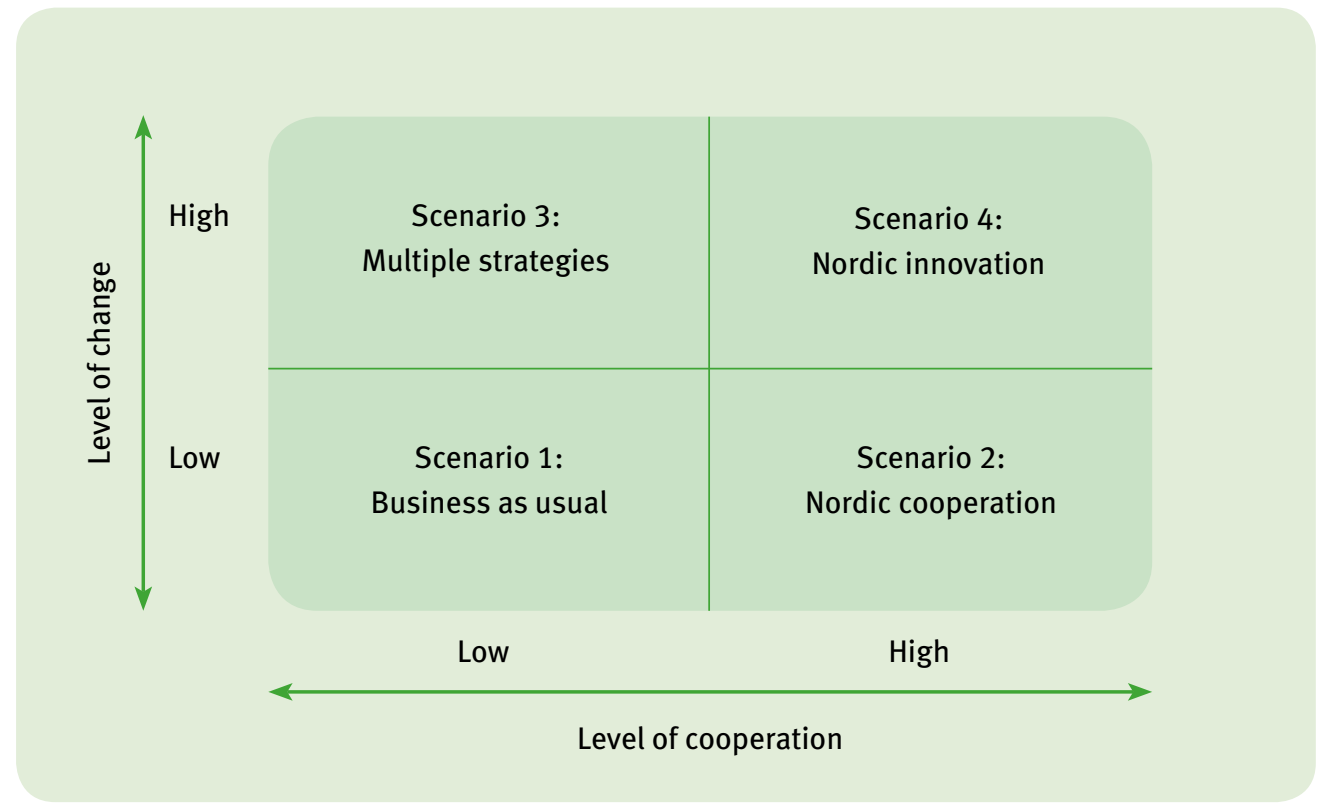

Figure 1. Different scenarios for future handling of used textiles 


\section{The proposed Nordic strategy}

The Nordic Strategy proposes 14 policy measures in order to achieve increased reuse and recycling of used textiles, giving a priority to reuse before recycling. It is crucial that the implementation of the targets and policy measures is supported and strengthened by appropriate structures, coordination, allocation of responsibilities and resources, milestones and follow-ups. The proposed measures are divided into four groups as follows:
Measures supporting the Nordic Commitment

1. Launch of the Nordic

Commitment

2. Expansion of the Nordic Commitment to include de-branding services

3. Engagement of municipalities in the Nordic Commitment

4. Further development of the Nordic Commitment to more actively involve and include textile producers
Measures supporting increased collection of textiles

5. Obligation for municipalities to secure that collection containers for textiles are available at all (municipal) recycling centres 6. Obligation to collect used textiles from public activities and public businesses

7. Introduction of a voluntary commitment for private companies to collect used textiles 


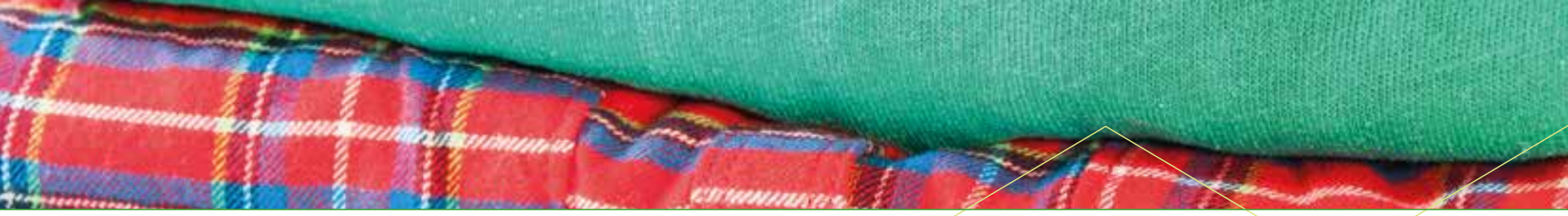

Measures supporting new business models

8. Evaluation of business models in the field of collective use, reuse and prolonged (active) lifetime of textiles

9. Government funding for startups in the field of collective use, reuse and prolonged (active)

lifetime of textiles

\section{Other supporting measures}

10. Consumer information campaign

11. Nordic Task Force for the Higg index

12. Public procurement for reuse of textiles and textiles with recycled content

13. Investigation of the need for and potentials of establishing an (automatic) sorting facility in the Nordic region

14. Financial assistance for establishing one chemical recycling facility on an industrial scale in the Nordic region

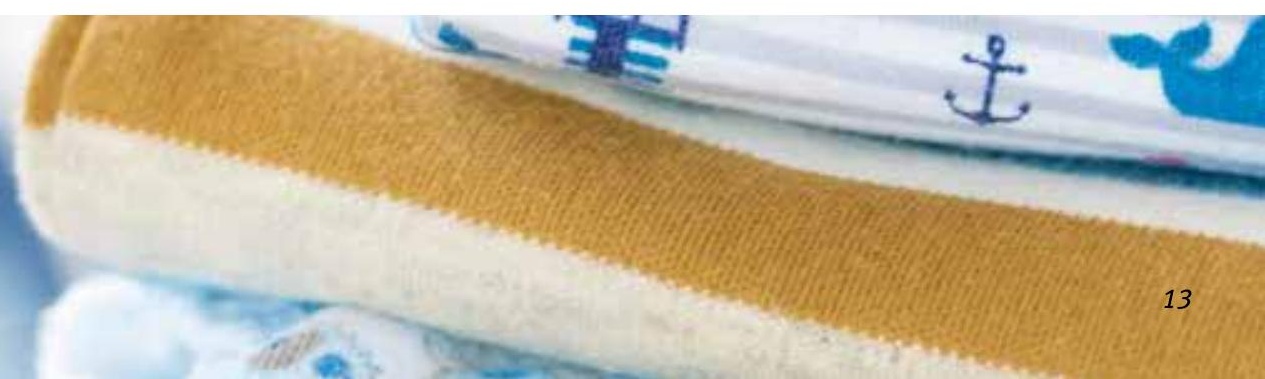




\section{Key actors for successful implementation}

Four main key actors for successful implementation of the Nordic

Strategy have been identified.

The Nordic Council of Ministers (NCM) and the Nordic Waste Group

(NAG) have played a central role for setting more efficient handling of textiles and textile wastes on the political agenda and can use the momentum to follow up on promising project results by financially supporting additional projects and investigations. The NCM/NAG could also play a central role in establishing a structure for Nordic cooperation within the field of textiles and textile wastes.

\section{National governments play}

a central role in establishing and implementing targets for improved handling of textiles and textile wastes. They would also be responsible for implementing suitable policy measures to reach such targets.

Municipalities were identified as key actors for implementation of four policy measures, including engagement in the Nordic Commitment, providing collection containers for textiles, collection of used textiles from municipal operations and applying public procurement guidelines for reuse and textiles with recycled content.

Entrepreneurs creating and applying new and alternative business models within the textile field could contribute to a successfully implemented strategy in terms of increasing collective use, reuse and prolonged (active) lifetime of textiles. They also play an important role in improving waste management of textile wastes by building new waste management infrastructures for sorting, de-branding and recycling of textiles. 


\section{Potentials for green jobs}

Increased reuse and recycling of textiles and textile wastes have potentials to create new green jobs, particularly in terms of collection, sorting, second hand retail and recycling of textiles.

Calculations on job creation are highly dependent on which types of organisations that will manage the increased collected amounts, on the amount of reusable items on the Nordic market and several other factors. Nevertheless, two examples can serve as an indication for potential increases in employment.
- Doubling the share of separate collection as aimed for in the Nordic textile reuse and recycling commitment would correspond to about 120000 tonnes of used textiles additionally collected. Using employee figures for Myrorna, the largest collector of textiles in Sweden, and putting it in relation to their collected amounts would imply 4400 new jobs and 30000 additional work training opportunities, internships and community service opportunities.
- Up to date, no functional facility for automated textile sorting exists. An estimate of additional jobs created in automated textile sorting can be carried out based on a level of 80000 tonnes of textiles annually. This would give similar amounts for automated sorting as a plastics sorting facility and would imply about 900 jobs, mostly in manual sorting of reusable textiles.

www.nordicway.org

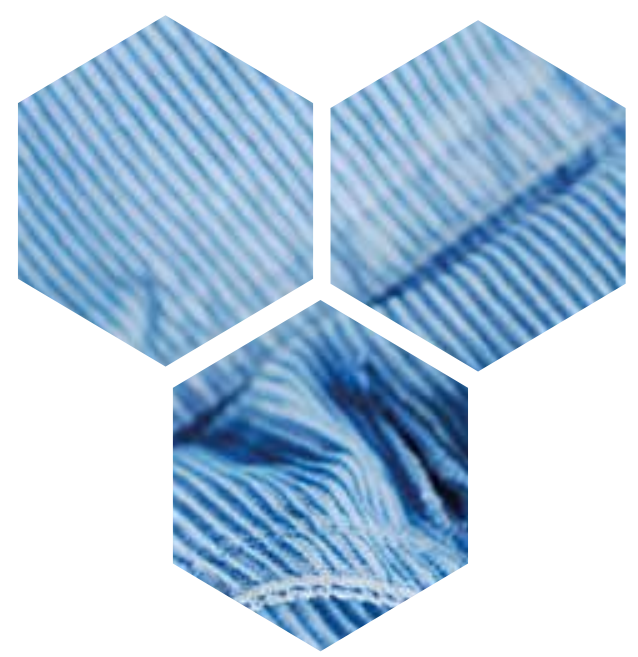




\section{norden}

Nordic Council of Ministers

Ved Stranden 18

DK-1061 København K

www.norden.org

This policy brief on Nordic textile reuse and recycling is part of the Nordic Prime Ministers' overall green growth initiative, The Nordic Region - leading in green growth. Read more in the web magazine Green Growth the Nordic Way at www.nordicway.org or at www. norden.org/greengrowth

ISBN 978-92-893-4021-2 (PRINT)

ISBN 978-92-893-4022-9 (PDF)

ANP 2015:720
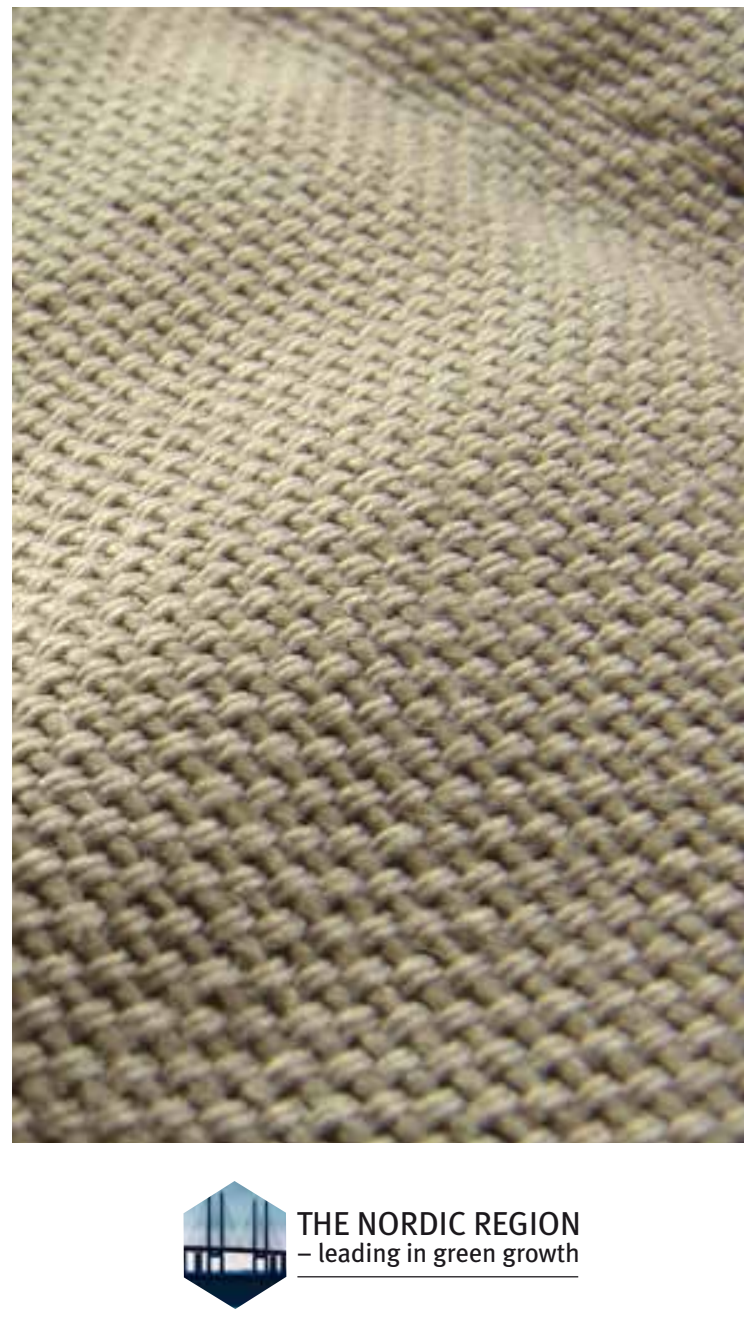